Pecvnia, Monográfico (2009), pp. 311-345

\title{
Nuevos estados integrantes de las cuentas anuales: el estado de flujos de efectivo y el estado de cambios en el patrimonio neto
}

\author{
Belén Morala Gómez \\ belen.morala@unileon.es \\ Universidad de León \\ Fac. de Ciencias Económicas y Empresariales \\ Campus de Vegazana, $\mathrm{s} / \mathrm{n}$ \\ 24071 León (España)
}

1. EL ESTADO DE FLUJOS DE EFECTIVO: OBJETIVOS Y UTILIDAD

La necesidad de que las sociedades informen acerca de los flujos de efectivo habidos durante el ejercicio ha sido una constante entre las demandas de los propios profesionales del mundo de la empresa. Su idea básica es la necesidad de complementar la tradicional información sobre el beneficio, basada en el principio del devengo, con información referente a flujos financieros, imprescindible cuando se trata de valorar la liquidez y solvencia de la empresa y menos susceptible de manipulación que la anterior, pues elimina partidas que no suponen cobros o pagos, tales como las provisiones y amortizaciones. 
También el Marco Conceptual del IASB (1989) reconoce la importancia de la información sobre flujos de efectivo para la toma de decisiones económicas por parte de los usuarios de la información financiera. Estos necesitan evaluar la capacidad de la empresa para generar efectivo u otros recursos equivalentes al efectivo, así como las fechas en que dicho efectivo se generará y la certidumbre relativa a su aparición.

Por su parte, la NIC 7 insiste en la importancia para los usuarios de la información relativa a cómo la empresa genera y utiliza el efectivo y equivalentes al efectivo, apuntando además que la relevancia de dicha información es independiente de la naturaleza de la empresa. En efecto, todas las empresas necesitan tesorería por las mismas razones: llevar a cabo sus actividades ordinarias, pagar sus obligaciones y remunerar a sus inversores.

Concretamente, el texto de la NIC 7 expone la siguiente serie de beneficios derivados de la información sobre flujos de efectivo:

a) Suministrar información que permite a los usuarios evaluar los cambios en los activos netos de la empresa, sus estructura financiera (incluyendo liquidez y solvencia) y su capacidad de modificar las fechas de los cobros y pagos a fin de adaptarse a las nuevas circunstancias y a las oportunidades que se puedan presentar.

b) Evaluar la capacidad de la empresa para generar efectivo y equivalentes al efectivo, permitiendo el desarrollo de modelos para evaluar y comparar el valor actual de los flujos netos de efectivo y el rendimiento de diferentes empresas.

c) Comprobar la exactitud de las evaluaciones pasadas respecto a los flujos futuros.

d) Analizar la relación entre rendimiento, flujos de efectivo netos y el impacto de los cambios en los precios.

En la misma línea se manifiesta el FASB (1995), que concreta las utilidades de la información sobre flujos de efectivo, cuando se usa en combinación con la relativa al resto de los estados financieros, en los siguientes aspectos:

a) Valorar la capacidad de la entidad para generar flujos de caja netos.

b) Valorar la capacidad de la entidad para satisfacer sus obligaciones externas a medida que vencen y sus necesidades de financiación externa. 
c) Determinar las diferencias entre el beneficio neto y los cobros y pagos asociados al mismo.

d) Conocer los efectos que sobre la posición financiera de la entidad tienen las actividades de inversión y financiación.

\section{PRESENTACIÓN DEL ESTADO DE FLUJOS DE EFECTIVO}

Como sucede con el resto de estados financieros, para que la información sobre flujos de efectivo sea realmente eficaz, esto es, consiga los objetivos enunciados en el apartado anterior, es precisa una presentación adecuada del correspondiente Estado de Flujos de Efectivo.

En este sentido, indica la NIC 7, el Estado de Flujos de Efectivo debe de informar acerca de los flujos de efectivo habidos durante el ejercicio, clasificándolos en actividades de explotación, de inversión y de financiación.

\subsection{Definición de flujos de efectivo}

En primer lugar, y sobre la propia definición de flujos de efectivo, se entiende por tales, las entradas y salidas de efectivo y equivalentes al efectivo. El efectivo está representado por la tesorería depositada en la caja de la empresa y los depósitos bancarios a la vista. Los otros activos líquidos equivalentes son instrumentos financieros a corto plazo (tres meses o menos), fácilmente convertibles en una cantidad determinada de efectivo, con un riesgo poco significativo de cambios en su valor y que forman parte de la política de gestión normal de la tesorería de la empresa.

En cuanto a la clasificación de los flujos de efectivo, es preciso definir claramente cada una de las categorías.

\subsection{Tipos de flujos de efectivo}

Los flujos de efectivo por operaciones de explotación son fundamentalmente los ocasionados por aquellas actividades que constituyen la fuente principal de ingresos ordinarios de la empresa, incluyéndose también en esta categoría otras actividades que no pueden calificarse como de inversión o financiación. 
Para identificar este tipo de flujos es necesario considerar la actividad de la empresa en cuestión. Así por ejemplo, los flujos de efectivo derivados de préstamos se clasificarán como procedentes de la explotación en las entidades financieras, al relacionarse con actividades que constituyen la principal fuente de ingresos de la empresa, en tanto que para la generalidad de las empresas constituirán flujos procedentes de operaciones de financiación.

A modo de ejemplo, la NIC 7 cita una serie de flujos de efectivo que normalmente se calificarán como procedentes de explotación, a saber:

- Cobros procedentes de la venta de bienes y prestación de servicios.

- Cobros procedentes de arrendamientos de patentes, cuotas, comisiones y otros ingresos ordinarios.

- Pagos a proveedores derivados del suministro de bienes y servicios.

- Pagos a los empleados.

- Cobros y pagos de las empresas de seguros como consecuencia de primas, prestaciones, anualidades y otras obligaciones derivadas de las pólizas suscritas.

- Cobros y pagos derivados de contratos de intermediación u otros acuerdos comerciales.

- Pagos o cobros derivados del impuesto sobre beneficios.

Por lo que se refiere a la utilidad de la información relativa al importe de los flujos de efectivo por actividades de explotación, debe señalarse que constituye un indicador clave para conocer en qué medida las mencionadas actividades han generado recursos suficientes para mantener la capacidad de explotación, así como excedentes que la empresa puede utilizar para pagar dividendos, devolver préstamos o realizar nuevas inversiones sin recurrir a nuevos préstamos.

Los flujos de efectivo por actividades de inversión representan desembolsos netos derivados de la adquisición, enajenación o abandono de activos a L/P, así como de inversiones no incluidas en el efectivo y los equivalentes de efectivo.

Los ejemplos que, sobre este tipo de flujos, propone la NIC 7, son los siguientes: 
- Cobros derivados de la venta de inmovilizado material, inmaterial, y otros activos a L/P.

- Pagos (cobros) por la adquisición (venta) de instrumentos de pasivo o de capital emitidos por otras empresas.

- Pagos y cobros derivados de anticipos de efectivo y préstamos a terceros.

- Pagos por la adquisición de elementos de inmovilizado material, inmaterial y otros activos fijos.

Por lo que se refiere a la interpretación de este tipo de flujos, un flujo neto positivo representa los recursos generados como consecuencia de la actividad desinversora de la empresa, en tanto que si es negativo, indica el importe de los recursos que la empresa ha destinado a incrementar sus inversiones, de las que se van a derivar ingresos y flujos de efectivo en el futuro.

Las actividades de financiación son aquellas que producen cambios en el tamaño y/o composición de los fondos propios y de los ajenos a largo o corto plazo de la empresa. Los flujos de efectivo por actividades de financiación se relacionan con aquellas operaciones de financiación que han supuesto flujos de efectivo y no aquellas pendientes de cobro o pago.

Ejemplos de este tipo de flujos serían los siguientes:

- Cobros procedentes de la emisión de acciones u otros instrumentos de capital.

- Cobros procedentes de la emisión de obligaciones, préstamos, bonos, cédulas hipotecarias y otros fondos tomados a préstamo, ya sea a largo o a corto plazo.

- Pagos a los propietarios por adquirir o rescatar las acciones de la empresa.

- Reembolso de los fondos tomados en préstamo.

El conocimiento de los flujos de efectivo por actividades de financiación permite realizar predicciones con respecto a las necesidades de efectivo para cumplir los compromisos con quienes suministran capital a la empresa. 
Por último, es necesario considerar que una única transacción puede incluir flujos de efectivo procedentes de distintos tipos de actividades. Así por ejemplo, el pago de la anualidad de un préstamo contiene además del importe principal, una parte de intereses. La devolución del principal corresponde a actividades de financiación. Por el contrario, el pago de la parte correspondiente a intereses se incluirá, como veremos posteriormente, en la categoría de flujos de explotación.

\section{actividades de explotación}

2.3. Determinación de los flujos de efectivo de las

Los distintos procedimientos para la determinación de los flujos de efectivo de explotación parten de la relación existente entre éstos y las partidas de la cuenta de resultados.

Se basan en la idea de que el beneficio o pérdida neta presentada en la cuenta de resultados coincidiría con el saldo neto de los flujos de efectivo de explotación si no fuera por una serie de diferencias sistemáticas entre ambas magnitudes.

Dichas diferencias son consecuencia de:

a) Gastos o ingresos sin reflejo en el efectivo

Existen, efectivamente, algunos gastos o ingresos que nunca afectarán al efectivo, puesto que no conllevan pagos o cobros. Ejemplos: pérdida por deterioro de existencias, amortizaciones del inmovilizado, dotación provisiones, pérdidas y ganancias de cambio no realizadas, trabajos realizados para el activo, etc.

b) Gastos o ingresos derivados de actividades de inversión o financiación

La cuenta de resultados puede incluir gastos o ingresos derivados de las actividades de inversión. Estos conceptos intervienen, evidentemente, en la determinación del beneficio neto y pueden llevar asociados flujos de efectivo, pero no deben incluirse entre las actividades de explotación. Ejemplo: ganancia en la venta de inmovilizado material.

c) Periodificación de ingresos y gastos

Siguiendo el principio del devengo hay ingresos y gastos del ejercicio que se pagan y cobran en otros periodos. Ejemplo: 
ventas a crédito realizadas en diciembre de 2006, a plazo de dos meses; son ingresos de 2006 pero no flujos de efectivo hasta 2007.

Identificadas las diferencias entre el resultado contable y los flujos de efectivo por operaciones de explotación, será ya posible y relativamente sencillo, partir de aquel para llegar a éste último. En este sentido, el importe de los flujos de efectivo por operaciones de explotación puede obtenerse siguiendo uno de los dos métodos siguientes:

\subsubsection{Método directo}

De acuerdo con el método directo, se presenta por separado cada una de las categorías de cobros y pagos que componen los flujos de efectivo de las operaciones de explotación.

La información necesaria para presentar los flujos de efectivo de explotación por el método directo puede obtenerse por cualquiera de las dos vías siguientes:

- Directamente de los registros contables de la empresa, o bien,

- A partir de los datos contenidos en la cuenta de resultados, procediendo de la siguiente manera:

Se descartan, en primer lugar, aquellas partidas de la cuenta de resultados que no supongan movimientos de efectivo, o bien, que correspondan a actividades de inversión o financiación.

En segundo lugar, se ajustan el resto de gastos e ingresos de acuerdo con la variación en las cuentas de existencias, cuentas a cobrar y cuentas a pagar de las actividades de explotación.

Por ejemplo, los ingresos por ventas contenidos en la cuenta de resultados, se transformarían en flujos de efectivo de la siguiente forma:

Ventas + saldo inicial de cuentas a cobrar - saldo final de cuentas a cobrar - cuentas a cobrar dadas de baja por insolvencias u otras causas - saldo inicial anticipos de clientes + saldo final anticipos de clientes

o lo que es lo mismo: 


\begin{abstract}
Ventas + / - variación saldo cuentas a cobrar - cuentas a cobrar dadas de baja por insolvencias u otras causas $+1-$ variación saldo anticipos de clientes
\end{abstract}

De la misma manera, partiendo de los gastos por compras, llegaríamos al importe de los pagos por dicho concepto durante el ejercicio, a través de los siguientes ajustes:

Compras + saldo inicial cuentas a pagar - saldo final cuentas a pagar - saldo inicial anticipos a proveedores + saldo final anticipos a proveedores

que expresado abreviadamente quedaría así:

Compras + / - variación saldo cuentas a pagar + / - variación saldo anticipos a proveedores

En general, los ajustes para transformar en flujos de efectivo cualquier gasto de explotación serían los siguientes:

Gastos de explotación - gastos anticipados inicio del ejercicio + gastos anticipados final de ejercicio + gastos diferidos inicio del ejercicio - gastos diferidos final de ejercicio

La presentación de los flujos de efectivo de explotación de acuerdo con el método directo tendría la siguiente forma:

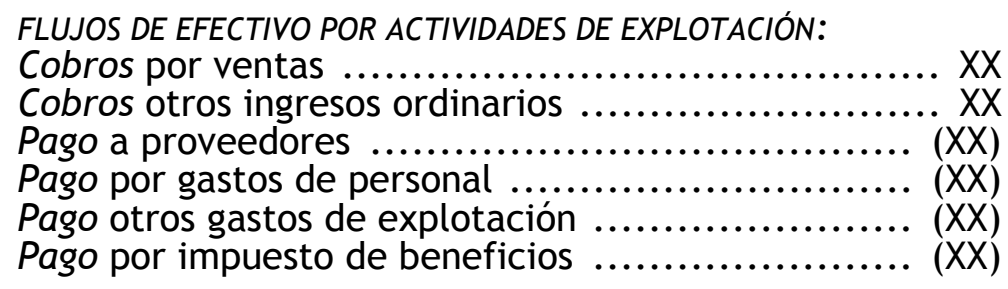

La NIC 7 recomienda a las empresas la presentación de los flujos de efectivo de explotación de acuerdo con este método. Las razones que lo justifican se centran, por una parte, en su utilidad a efectos de estimar los flujos futuros de efectivo, utilidad que no se consigue cuando se utiliza el método indirecto, que comentaremos a continuación. Por otra parte, la presentación por el método directo mejora la claridad y comprensión, al permitir a los usuarios entiendan cómo se generan y utilizan los distintos flujos de efectivo, información que no les ofrece ni 
el balance ni la cuenta de resultados. Además, dado que los cobros y pagos que presenta el estado de flujos no dependen de los métodos contables empleados en el tratamiento de las distintas partidas, la comparabilidad entre empresas se ve notablemente reforzada.

En cuanto a los inconvenientes del método directo, en la literatura contable únicamente se hace referencia al coste de obtención de la información necesaria para su formulación, los que ha llevado a algunas normas a permitir también el método indirecto $\mathrm{y}$, a otras, a decantarse claramente por este último, como es el caso español.

\subsubsection{Método indirecto}

Utilizar el método indirecto supone calcular de forma global el flujo de efectivo por actividades de explotación en vez de determinar uno a uno sus elementos. El cálculo parte, en este caso, del resultado del ejercicio, sobre el que se practican determinadas correcciones, concretamente, las siguientes:

- Partidas que no suponen movimientos de efectivo (amortizaciones, deterioros de valor...).

- Variaciones en las cuentas de existencias, cuentas a cobrar y a pagar por actividades de explotación.

- Gastos e ingresos por actividades de inversión o financiación.

De acuerdo con ello, la presentación de los flujos de efectivo de explotación siguiendo el método indirecto adoptaría la siguiente forma:

Resultado de las actividades ordinarias

+ Amortizaciones

+ Deterioros de valor

+ / - Diferencias de cambio no realizadas

+ / - Otros gastos e ingresos ordinarios que no suponen desembolso

+ / Ajustes por ingresos y gastos de actividades de inversión o financiación

Resultado ordinario antes de variaciones en el capital circulante + / - Variación en las cuentas de existencias

+/ - Variación en cuentas a cobrar por operaciones de explotación

+/ - Variación en cuentas a pagar por operaciones de explotación 
2.4. Determinación de los flujos de efectivo por operaciones de inversión y financiación

Para el cálculo de este tipo de flujos existen dos opciones:

1) Partir de los datos contenidos en los registros contables, o bien,

2) Utilizar la información contenida en otros estados financieros.

En este último caso, es necesario tener en cuenta que las actividades de inversión y financiación generalmente tienen su reflejo en Balance, concretamente en el activo las de inversión y en el pasivo las correspondientes a la financiación.

En este sentido, en muchos casos, las variaciones en los saldos de las cuentas correspondientes al balance, complementadas con datos acerca de las pérdidas y ganancias que dichas actividades hayan generado, indican los correspondientes flujos de efectivo.

No obstante, puede existir cierta complicación cuando en un mismo ejercicio se producen movimientos de signo opuesto en la misma cuenta de activo o pasivo (ocurre una compra y una venta de maquinaria, o el reembolso y obtención de un préstamo). También, es preciso tener en cuenta que no todos los movimientos en cuentas de activo o pasivo llevan asociado un flujo de efectivo (ejemplos de estas situaciones serían el traspaso de beneficios a cuentas de reservas o las reclasificaciones de deudas). Por último, hay que considerar que la compra o venta de un activo no suponen necesariamente un pago o un cobro en el mismo ejercicio.

Como conclusión, habría que recurrir entonces, a datos mas desagregados sobre los movimientos de las cuentas afectadas.

\subsection{Otras cuestiones a considerar en la elaboración del EFE}

dividendos

2.5.1. Flujos de efectivo procedentes de intereses y

Los flujos de efectivo correspondientes a estas operaciones deben presentarse, de acuerdo con la NIC 7, por separado, de manera consistente período a período; no obstante, no existen normas precisas sobre su clasificación como actividades de explotación, inversión o financiación.

Por lo que se refiere a los intereses pagados e intereses y dividendos percibidos, podrían considerarse alternativamente como flujos 
de explotación, si nos atenemos al hecho de que participan en la determinación del resultado neto, pero además, teniendo en cuenta que los intereses pagados representan costes derivados de la obtención de recursos ajenos, podríamos clasificarlos como flujos de financiación, mientras que los dividendos e intereses percibidos, al ser rendimientos de inversiones financieras, podrían ubicarse como flujos de inversión.

Con respecto a los dividendos pagados las alternativas serían considerarlos como flujos de actividades de financiación, pues representan el coste de obtener recursos financieros, o bien, presentarlos como flujos de explotación, lo cual resultaría útil al permitir a los usuarios valorar la capacidad de la empresa para atender los dividendos con flujos de explotación.

2.5.2. Flujos de efectivo procedentes de operaciones en moneda extranjera

Los flujos derivados de transacciones en moneda extranjera se convierten en moneda nacional aplicando el tipo de cambio existente en la fecha en la que se produjo la entrada o salida. No obstante, en ocasiones y por razones prácticas, se utiliza un tipo de cambio promedio de los tipos de cambio de un período para contabilizar las operaciones en moneda extranjera, siempre que se aproxime al cambio efectivo del conjunto de transacciones y que los tipos de cambio no fluctúen de manera significativa.

Las pérdidas o ganancias no realizadas, por diferencias de cambio en moneda extranjera, no producen flujos de efectivo. No obstante, el efecto de la variación de los tipos de cambio procedente de partidas de efectivo o equivalentes al efectivo debe presentarse en una partida específica, separada de los flujos de explotación, inversión y financiación, a los efectos de permitir la conciliación entre las existencias iniciales y finales de efectivo.

sociedades

2.5.3. Flujos de efectivo derivados de impuesto sobre

Evidentemente, los impuestos sobre las ganancias surgen en actividades de explotación, inversión y financiación. No obstante, suele ser difícil asociar los flujos de efectivo con las distintas actividades, puesto 
que los mismos, se pueden producir en ejercicios distintos a aquellos en los que ocurren las transacciones.

Consecuentemente, los impuestos pagados se suelen clasificar como flujos de actividades de explotación, sin perjuicio de que, como indica la NIC 7, cuando sea posible asociarlos a operaciones de inversión o financiación se clasifiquen de la misma forma que la transacción a la que se refieren.

2.5.4. Flujos de efectivo derivados de adquisiciones y enajenaciones de dependientes y otras unidades de negocio

Los flujos de efectivo agregados derivados de adquisiciones y enajenaciones de filiales y otras empresas deben mostrarse por separado y clasificarse como actividades de inversión.

La presentación separada ayudará a distinguir estos flujos de aquellos que surgen en las operaciones de explotación, financiación y otras actividades de inversión.

Por otra parte, y por razones eminentemente informativas, no podrán compensarse los flujos de efectivo procedentes de enajenaciones con los correspondientes a adquisiciones.

De esta forma, el estado de flujos presentará los importes agregados netos que se pagan o se cobran por la compra o enajenación de una empresa.

\subsubsection{Flujos de efectivo en términos netos}

Pueden presentarse en términos netos los flujos de efectivo correspondientes a cobros y pagos procedentes de partidas en las que la rotación es elevada, los importes altos y el vencimiento próximo. Ejemplos de este tipo de flujos serían los correspondientes a la compra y venta de inversiones financieras o préstamos tomados a corto plazo (tres meses o menos).

También la NIC 7 permite presentar en términos netos los cobros y pagos por cuenta de clientes, siempre que los flujos de efectivo reflejen la actividad del cliente en mayor medida que la de la empresa. En este sentido, la citada norma propone los siguientes ejemplos: aceptación y reembolso de depósitos a la vista por parte de un banco, fondos de 
clientes que posee una empresa dedicada a la intermediación financiera o los alquileres cobrados de los clientes y posteriormente pagados a los propietarios de propiedades inmobiliarias.

\subsubsection{Transacciones no monetarias}

Las transacciones no monetarias representan operaciones de inversión o financiación que no tienen impacto directo en los flujos de efectivo, a pesar de modificar la estructura del activo y/o del pasivo. Son transacciones no monetarias las siguientes:

- Adquisición de activos, asumiendo simultáneamente un pasivo para su financiación, o a través de un contrato de arrendamiento financiero.

- Compra de una empresa a través de una ampliación de capital.

- Conversión de deuda en patrimonio neto.

Las transacciones no monetarias se excluirán del estado de flujos de efectivo, no obstante, se informará sobre las mismas en otros estados financieros, a fin de suministrar a los usuarios toda la información relevante sobre las actividades de inversión y financiación.

\section{Valor Añadido}

2.5.7. Flujos de efectivo derivados del Impuesto sobre el

El tema del Impuesto sobre el Valor Añadido no aparece contemplado de forma expresa ni en la Norma Internacional, ni tampoco en el vigente Plan General de Contabilidad.

Ahora bien, es necesario tener en cuenta que los cobros o pagos correspondientes a operaciones gravadas con este impuesto incluyen el IVA correspondiente, por lo que lo lógico será presentar dichos cobros y pagos por su importe bruto.

Por otra parte, al ser el IVA un impuesto indirecto, la empresa actúa como simple intermediaria, de manera que la diferencia entre el IVA repercutido y soportado en las distintas operaciones gravadas por el impuesto genera también un flujo de efectivo. Este último se puede materializar en el propio ejercicio o en ejercicios siguientes, puesto 
que el pago se efectúa trimestralmente y se permite su compensación en ejercicios posteriores.

Por último, por lo que hace referencia a la ubicación dentro del Estado de Flujos de Efectivo de estos cobros o pagos, y teniendo en cuenta lo dispuesto para el caso del impuesto sobre beneficios, parece lógico pensar que cuando la diferenciación entre el importe de los mencionados flujos que corresponda a actividades de explotación y a actividades de inversión resulte difícil de establecer, los mismos se considerarán como flujos de efectivo por operaciones de explotación.

\section{EL ESTADO DE FLUJOS DE EFECTIVO EN EL VIGENTE PLAN GENERAL DE CONTABILIDAD}

Las precisiones que contiene nuestro vigente PGC con respecto al estado de flujos presentado en la NIC 7, que ha sido objeto de estudio en la primera parte de este artículo son las siguientes:

Con respecto a la presentación de los flujos de efectivo por operaciones de explotación, el Plan se decide por el método indirecto, método que como ya comentamos anteriormente, ofrece mayor simplicidad en cuanto a cálculos, pero presenta, por el contrario, grandes desventajas informativas.

Seleccionado este método, el importe de partida para el cálculo de los flujos de explotación es el correspondiente al resultado antes de impuestos, pues, como podemos observar en el modelo, el pago por impuesto de sociedades se desglosa de manera específica.

El resultado antes de impuestos se corrige con el fin de eliminar los gastos e ingresos que no han supuesto movimiento de efectivo, los procedentes de actividades de inversión y financiación e incorporar transacciones de ejercicios anteriores cobradas o pagadas en el actual, en concreto, se presentarán por separado los siguientes conceptos:

A) Ajustes del resultado:

- Correcciones valorativas (amortizaciones, pérdidas por deterioro de valor, resultados por aplicación del valor razonable y variaciones de provisiones). 
- Operaciones que deben clasificarse como actividades de inversión o financiación (resultados por enajenación de inmovilizado o de instrumentos financieros).

- Remuneración de activos y pasivos financieros, cuyos flujos de efectivo se mostrarán en un epígrafe aparte.

B) Cambios en el capital corriente: por diferencia en el tiempo entre la corriente real y monetaria de bienes y servicios (Variación existencias, deudores y otras cuentas a cobrar, acreedores y otras cuentas a pagar...).

C) Flujos por intereses y cobros de dividendos.

D) Flujos por impuesto sobre beneficios.

En consecuencia, el modelo propone informar separadamente de los flujos de efectivo procedentes de la remuneración de activos y pasivos financieros (intereses cobrados y pagados y dividendos percibidos) y de los pagos por impuesto de beneficios.

Por otra parte, las opciones que planteaba la NIC 7 con respecto a la consideración de los flujos correspondientes a la remuneración de activos y pasivos financieros, y que ya comentamos en un epígrafe previo, se resuelven en el Plan asignando estos flujos a la categoría de flujos de explotación.

Por último, los pagos a favor de accionistas en concepto de dividendos, para los que la NIC 7 también establecía distintas alternativas, se incluyen en el PGC como flujos de efectivo por actividades de financiación.

Ejemplo n ${ }^{0}$ 1.- Elaboración del Estado de Flujos de Efectivo

Proponemos, a continuación, un caso muy sencillo para ilustrar la presentación del estado de Flujos de Efectivo de acuerdo con el PGC.

La sociedad TALVASA presenta, a 31-12-08 los siguientes saldos en su Balance de Situación: 


\begin{tabular}{|c|c|c|}
\hline ACTIVO & 2008 & 2007 \\
\hline A) ACTIVO NO CORRIENTE . & 1.470 & 1.200 \\
\hline II. Inmovilizado material . & 1.470 & 1.200 \\
\hline B) ACTIVO CORRIENTE . & 1.500 & 1.650 \\
\hline II. Existencias ... & 150 & 450 \\
\hline III. Deudores comerciales y otras cuentas a cobrar .......... & 600 & 300 \\
\hline VII. Efectivo y otros activos líquidos equivalentes .......... & 750 & 900 \\
\hline 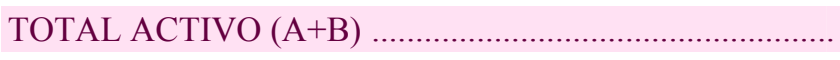 & 2.970 & 2.850 \\
\hline PATRIMONIO NETO Y PASIVO & 2008 & 2007 \\
\hline A) PATRIMONIO NETO & 1.860 & 1.500 \\
\hline A-1) Fondos propios & 1.860 & 1.500 \\
\hline I. Capital & 1.500 & 1.200 \\
\hline III. Reservas ........................... & 300 & 300 \\
\hline VII. Resultado del ejercicio ............ & 60 & 0 \\
\hline B) PASIVO NO CORRIENTE ........ & 570 & 690 \\
\hline 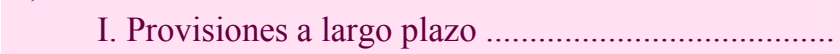 & 120 & 0 \\
\hline 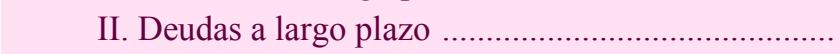 & 450 & 690 \\
\hline C) PASIVO CORRIENTE & 540 & 660 \\
\hline V. Acreedores comerciales y otras cuentas a pagar ... & 540 & 660 \\
\hline 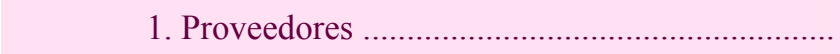 & 480 & 510 \\
\hline 5. Pasivos por impuesto corriente ............................. & 60 & 0 \\
\hline 6. Otras deudas con Administraciones Públicas ... & 0 & 150 \\
\hline TOTAL PATRIMONIO NETO Y PASIVO $(\mathrm{A}+\mathrm{B}+\mathrm{C})$ & 2.970 & 2.850 \\
\hline
\end{tabular}

Por otra parte, los datos de la cuenta de pérdidas y ganancias son los siguientes:

\begin{tabular}{|c|c|}
\hline \multicolumn{2}{|l|}{ 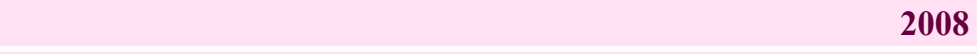 } \\
\hline 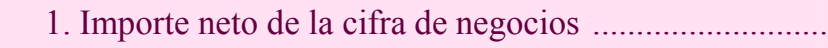 & 900 \\
\hline 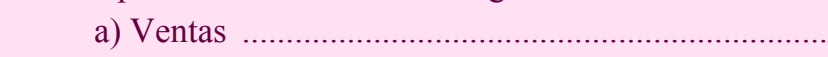 & 900 \\
\hline 4. Aprovisionamientos ....... & $(540)$ \\
\hline a) Consumo de mercaderías & $(540)$ \\
\hline 7. Otros gastos de explotación. & $(120)$ \\
\hline 8. Amortización del inmovilizado & $(30)$ \\
\hline A.1) RESULTADO DE EXPLOTACIÓN . & 2 \\
\hline 13. Gastos financieros .. & (9) \\
\hline A.2) RESULTADO FINANCIERO & $(90)$ \\
\hline A.3) RESULTADO ANTES DE IMPUESTOS & \\
\hline 17. Impuesto sobre beneficios & $(6$ \\
\hline A.5) RESULTADO DEL EJERCICIO & \\
\hline
\end{tabular}

Información adicional: 
- Durante el ejercicio se ha llevado a cabo una ampliación de capital por valor de 300 u.m., que ha sido integramente desembolsada por los accionistas.

- El apartado "otros gastos de explotación" recoge la cuantía estimada de la indemnización a la que probablemente tendrá que hacer frente la empresa como consecuencia de un litigio en curso. La contrapartida ha sido la cuenta "Provisión para otras responsabilidades".

- Se pagan 150 u.m. correspondientes a una deuda que se mantenía con Hacienda.

- El gasto por Impuesto de Sociedades del ejercicio asciende a 60 u.m. y queda pendiente de pago.

- Durante el ejercicio se ha adquirido al contado diverso inmovilizado material por importe de 300 u.m.

- La variación en las deudas a largo plazo se ha satisfecho totalmente en efectivo.

Se pide: Elaborar el Estado de Flujos de Efectivo.

\section{Solución.-}

\section{ESTADO DE FLUJOS DE EFECTIVO}

A) FLUJOS DE EFECTIVO DE LAS ACTIVIDADES DE EXPLOTACIÓN

1. Resultado del ejercicio antes de impuestos

2. Ajustes del resultado

a) Amortización del inmovilizado $(+)$..................................... $\quad 30$

c) Variación de provisiones $(+/-)$......................................... 120

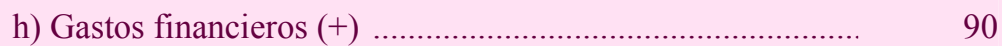

3. Cambios en el capital corriente ............................................ (180)

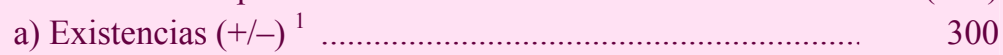

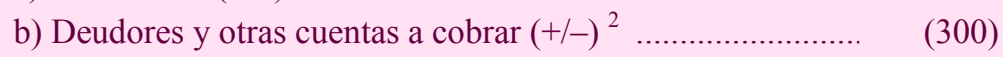

d) Acreedores y otras cuentas a pagar $(+/-)^{3} \ldots \ldots \ldots \ldots \ldots \ldots \ldots \ldots \ldots \ldots \ldots \ldots \ldots \ldots$ (180)

4. Otros flujos de efectivo de las actividades de explotación ....... (90)

a) Pagos de intereses $(-)$.................................................. (90)

d) Pagos (cobros) por impuesto sobre beneficios $(-/+) \ldots \ldots \ldots . . . \quad 0$

5. Flujos de efectivo de las actividades de explotación ................ $\quad 90$

B) FLUJOS DE EFECTIVO DE LAS ACTIVIDADES DE INVERSIÓN

6. Pagos por inversiones (-)

c) Inmovilizado material

8. Flujos de efectivo de las actividades de inversión

C) FLUJOS DE EFECTIVO DE LAS ACTIVIDADES DE FINANCIACIÓN

9. Cobros y pagos por instrumentos de patrimonio

a) Emisión de instrumentos de patrimonio (+) ....................... 300

10. Cobros y pagos por instrumentos de pasivo financiero .......... (240)

b) Devolución y amortización de

2. Deudas con entidades de crédito $(-)^{4}$

12. Flujos de efectivo de las actividades de financiación 
D) EFECTOS DE LAS VARIACIONES DE LOS TIPOS DE CAMBIO

E) AUMENTO/DISMINUCIÓN DE EFECTIVO O EQUIVAL. ....................... (150)

Efectivo o equivalentes al comienzo del ejercicio ...................... 900

Efectivo o equivalentes al final del ejercicio ............................. 750

(1) Disminución en la cuenta de existencias (150-450), registrada en la cuenta de resultados y que no conlleva flujo negativo de tesorería.

(2) Aumento en deudores y otras cuentas a cobrar (600-300), con una repercusión negativa sobre los flujos de efectivo.

(3) Disminución en acreedores y otras cuentas a pagar, salvo la correspondiente al pasivo por impuesto corriente, que se desglosa por separado: $[480-(510+150)]=(480-660)=-180$. El efecto de esta disminución sobre los flujos de tesorería es negativo.

(4) Disminución, en efectivo, de las deudas a largo plazo: $(450-690)=240$

\section{EL ESTADO DE CAMBIOS EN EL PATRIMONIO NETO}

El vigente Plan General de Contabilidad entiende este nuevo estado financiero como un documento contable que pone de manifiesto todas las variaciones experimentadas por el patrimonio neto de la empresa. Así, frente a las dos alternativas contempladas en la NIC1:

- La presentación de un estado que muestre todos los cambios habidos en el patrimonio neto, o bien

- Los cambios en el patrimonio neto distintos de los procedentes de las transacciones con los propietarios del mismo, cuando actúen como tales,

la norma española se ha decidido por la opción más amplia, presentando, por lo tanto, en el cuerpo del estado todos los cambios en el patrimonio neto, si bien, como veremos, a efectos informativos, los mismos aparecen convenientemente clasificados en función de su origen.

La información que proporciona este nuevo estado puede entenderse como un adecuado complemento a la información ofrecida por los estados contables tradicionales. Así, mientras el balance de situación solamente recoge la situación inicial y final de cada partida de patrimonio neto, el nuevo estado explica qué operaciones han producido el paso de una a otra. Por otra parte, el nuevo estado recoge pérdidas y ganancias derivadas de las modificaciones de valor de algunos elementos patrimoniales, que no figuran en la cuenta de resultados tradicional, y que permiten determinar las pérdidas y ganancias totales generadas por la entidad a lo largo del período considerado. 
En cuanto a los potenciales usuarios de este estado, el complemento que ofrece a la información proporcionada por el balance y la cuenta de resultados lo convierte en útil para todos ellos. No obstante sí existen dos grupos para los que la información va a ser especialmente interesante: accionistas y acreedores, además de los directivos y administradores de la propia empresa. En el caso de los accionistas, el estado les sirve para conocer cómo evoluciona la riqueza de la empresa, y en consecuencia, el valor de sus participaciones. Los acreedores, por su parte, necesitarán la información ofrecida por el nuevo estado para formarse una opinión acerca las garantías que les ofrece la empresa con respecto al pago de sus deudas.

\subsection{El concepto de Patrimonio Neto}

Considerando que el objetivo del Estado de Cambios en el Patrimonio Neto es, como acabamos de ver, mostrar todas las variaciones habidas en el patrimonio neto de una empresa, parece lógico comenzar su estudio tratando de determinar qué se entiende por patrimonio neto.

En este sentido, el PGC, en sintonía con las NIC, define el patrimonio neto de forma residual y no como suma de los conceptos que lo integran. Así, el cuarto apartado de la primera parte del Plan (Marco Conceptual de la Contabilidad), dedicado a los elementos de las cuentas anuales, considera el patrimonio neto como uno de los elementos integrantes del balance, definiéndolo como:

la parte residual de los activos de la empresa, una vez deducidos todos sus pasivos. Incluye las aportaciones realizadas, ya sea en el momento de la constitución o en otros posteriores, por sus socios o propietarios, que no tengan la consideración de pasivos, así como los resultados acumulados u otras variaciones que le afecten.

Como podemos observar, la propia definición añade la clasificación, a efectos de presentación, de los distintos componentes del patrimonio neto.

Por lo que se refiere a las aportaciones de socios o propietarios, están constituidas por el capital y la prima de emisión y se presentan en la rúbrica A-1) Fondos propios, del patrimonio neto en el balance de situación. 
Por lo que se refiere al capital, es necesario destacar y comentar algunas cuestiones.

En primer lugar, la creciente diversidad de instrumentos financieros plantea, en ocasiones, problemas para diferenciar las aportaciones a título de capital de los pasivos exigibles. En estos casos, resulta útil tomar en consideración las previsiones de la NIC 32 relativas a las condiciones que debe reunir un instrumento de capital, a saber:

a) Un instrumento de capital no incluye obligación contractual de:

- entregar dinero u otro activo financiero a otra entidad,

- intercambiar activos financieros o pasivos financieros con otra entidad en circunstancias potencialmente desfavorables para el emisor.

b) $\mathrm{Si}$ el instrumento es o puede ser liquidado mediante un instrumento de capital propio del emisor, debe ser:

- Un instrumento no derivado que no incluye obligación contractual para el emisor de entregar un número variable de sus instrumentos de capital propio.

- Un instrumento derivado que sólo será liquidado por el emisor intercambiando un importe fijo de efectivo u otros activos financieros por un número fijo de sus instrumentos de capital propio.

De acuerdo con la primera de las condiciones expuestas, las acciones preferentes que prevean, entre sus condiciones de emisión, la recompra obligatoria por parte del emisor, en una fecha y a un precio determinados o determinables, o bien, proporcionen a su tenedor el derecho a exigir el rescate en una fecha e importe determinados o determinables, se clasificarán como instrumentos de pasivo financiero.

La misma clasificación resultará aplicable a las obligaciones perpetuas, pues aunque sus titulares no tuvieran siquiera el derecho al reembolso del capital, sí poseen, en cambio, el derecho a la remuneración periódica correspondiente.

Teniendo en cuenta la segunda de las condiciones, los contratos que supongan la obligación, por parte de la entidad, de entregar un número variable de acciones $u$ otros instrumentos financieros, de forma que el valor razonable de los instrumentos a entregar sea equivalente al 
valor razonable de la obligación, deben clasificarse como pasivos financieros. Por el contrario, cuando la obligación de la entidad consistiera en la entrega de un número fijo de acciones, procedería su clasificación como instrumentos de capital. Puede justificarse que, en el primer caso, los tenedores de tales instrumentos financieros no asumen los riesgos inherentes a la actividad empresarial, en tanto que sí los soportan en el segundo.

En segundo lugar, hay que considerar también la existencia de instrumentos financieros compuestos, con un componente de pasivo y otro de fondos propios. Es el caso de las obligaciones convertibles en acciones. Se exige, entonces, la valoración por separado de ambos componentes.

Por último, otras cuestiones relaciones relacionadas con el capital que pueden plantear problemas en cuanto a su consideración contable, son las acciones propias y el capital pendiente de desembolsar.

En cuanto a las acciones propias, independientemente de los objetivos que se persigan con su adquisición, deben deducirse de los fondos propios pues suponen, en definitiva, una devolución de aportaciones a los propietarios. Por otra parte, el capital pendiente de desembolsar representa un compromiso de los accionistas de aportar capital, por lo tanto, éste no puede considerarse completo mientras no esté íntegramente desembolsado.

Con respecto al segundo componente del patrimonio neto, los resultados acumulados, podemos efectuar una distinción entre los beneficios pendientes de distribución y las reservas. Los primeros formarán parte del patrimonio hasta que se decida su distribución, momento en que la parte destinada a socios o accionistas minorará dicho patrimonio neto, en tanto que la parte retenida continuará formando parte del mismo en la correspondiente cuenta de reservas.

Las reservas, por su parte, proceden de beneficios que la empresa ha obtenido y que no ha repartido entre sus socios o accionistas, clasificándose en distintas cuentas en función de los motivos para su creación (reserva legal, estatutaria, voluntaria, por fondo de comercio...).

El tercero de los componentes del patrimonio neto al que hace referencia el nuevo PGC, las otras variaciones en el patrimonio neto, figura en las rúbricas A-2) y A-3) del patrimonio neto en el balance de situación. Se trata de los ajustes por cambios de valor y de las subvenciones, donaciones y legados recibidos.

Los ajustes por cambios de valor proceden de variaciones de valor de los elementos del balance de situación, que no se han imputado 
al resultado del ejercicio sino directamente al patrimonio neto. Pueden diferenciarse distintos tipos de variaciones en función de su origen: variaciones derivadas de la aplicación del valor razonable a instrumentos financieros disponibles para la venta, variaciones derivadas de operaciones de cobertura y variaciones en la valoración de activos no corrientes y grupos enajenables mantenidos para la venta.

Las subvenciones, donaciones y legados recibidos se tratan contablemente como ingresos, que se imputan inicialmente al patrimonio neto, para posteriormente, traspasarse a la cuenta de pérdidas y ganancias de forma correlacionada con los gastos derivados de la subvención, donación o legado.

Neto

\subsection{Presentación del Estado de Cambios en el Patrimonio}

Como ya apuntábamos al comienzo, el modelo de Estado de Cambios en el Patrimonio Neto que propone la norma española se corresponde con un modelo integral, es decir, un modelo que muestra todos los cambios habidos en el patrimonio neto de una empresa a lo largo del ejercicio. Consta de dos partes:

- El Estado de gastos e ingresos reconocidos,

- El Estado total de cambios en el patrimonio neto.

\subsubsection{El Estado de gastos e ingresos reconocidos}

Recoge cambios en el patrimonio neto derivados de:

- El resultado del ejercicio de la cuenta de Pérdidas y ganancias.

- Los ingresos y gastos que, de acuerdo con las normas de valoración deben imputarse al patrimonio neto.

- Transferencias a la cuenta de Pérdidas y Ganancias de los ingresos y gastos anteriores.

Para entender adecuadamente el sentido de la presentación de esta primera parte del estado, es preciso considerar el nuevo concepto de resultado contable derivado de la adaptación a la legislación internacional. Ésta otorga un papel fundamental a los activos y pasivos. De hecho, el Marco Conceptual define tanto el patrimonio neto como los ingresos y gastos por referencia a dichos elementos. Así, considera el 
patrimonio neto como la parte residual de los activos de la empresa una vez deducidos sus pasivos. Los ingresos (gastos) se definen como incrementos (decrementos) en el patrimonio neto de la empresa durante el ejercicio, en forma de aumentos (disminuciones) en el valor de los activos o disminuciones (aumentos) de los pasivos que no tengan su origen en aportaciones de los socios o propietarios.

De lo anterior se derivan importantes implicaciones para el resultado contable.

Por una parte, no se exige que los ingresos y gastos se hayan realizado, sino que lo importante es que se hayan devengado. Por lo tanto, formarán parte del resultado del ejercicio tanto los resultados de las actividades de la empresa (algunos de los cuales pueden no estar realizados) como los resultados por tenencia de activos, que representarían plusvalías o minusvalías devengadas pero no realizadas.

Por otra parte, los ingresos y gastos pueden aparecer bien en la cuenta de pérdidas y ganancias, o bien, directamente en el patrimonio neto. De aquí el interés por esta primera parte del estado, el Estado de gastos e ingresos reconocidos, que presenta de forma conjunta todos ellos.

Por lo que se refiere a los ingresos y gastos que, de acuerdo con las normas de valoración, deben imputarse al patrimonio neto, resultan de la suma de los siguientes epígrafes:

- Por valoración de activos

- Por coberturas

- Diferencias de conversión

- Subvenciones de capital

- Efecto impositivo de los ingresos y gastos imputados directamente al patrimonio neto

Con respecto al último de los ellos, merece la pena comentar que, entre las normas de elaboración del estado, figura la obligación de presentar en el mismo, los ingresos y gastos imputados directamente al patrimonio neto y las transferencias a la cuenta de pérdidas y ganancias por su importe bruto, mostrando en una partida separada su correspondiente efecto impositivo. De esta forma se justifica la inclusión de este último epígrafe.

El apartado "Transferencias a la cuenta de pérdidas y ganancias" informa de aquellos gastos e ingresos imputados directamente 
al patrimonio neto que, como consecuencia de circunstancias tales como la enajenación de un activo disponible para la venta o la amortización o baja en inventario de un activo subvencionado, deben ser trasladados a la cuenta de pérdidas y ganancias.

\subsubsection{El Estado total de cambios en el patrimonio neto}

Esta segunda parte del estado informa de todos los cambios habidos en el patrimonio neto derivados de:

- El saldo total de los ingresos y gastos reconocidos.

- Las variaciones originadas en el patrimonio neto por operaciones con los socios o propietarios cuando actúen como tales.

- Las restantes variaciones que se produzcan en el patrimonio neto.

- Ajustes al patrimonio neto debidos a cambios en los criterios contables y corrección de errores.

El primero de los epígrafes, saldo total de los ingresos y gastos reconocidos, procede, evidentemente, de la primera parte del estado. Por lo que se refiere al segundo, operaciones con socios y propietarios, se obtiene de la consideración de las siguientes situaciones:

- Ampliaciones de capital.

- Reducciones de capital.

- Conversión de pasivos financieros en patrimonio neto (obligaciones en acciones).

- Distribución de dividendos.

- Operaciones con acciones o participaciones propias.

- Incremento o reducción del patrimonio neto resultante de una combinación de negocios.

- Emisión o cancelación de otros instrumentos de patrimonio propio.

Las restantes variaciones en el patrimonio neto, el tercer epígrafe, queda explicado en las normas de elaboración del estado, hace referencia a las posibles aplicaciones del resultado del ejercicio anterior que supongan reclasificaciones de partidas de patrimonio neto (parte del resultado destinado a reservas).

En cuanto a los ajustes al patrimonio neto debidos a cambios en los criterios contables y corrección de errores, es preciso recordar que 
la norma de valoración $\mathrm{n}^{\circ} 22$ del vigente PGC exige que, al efectuar cambios en los criterios contables o subsanar errores de ejercicios anteriores, se practiquen ajustes retrospectivos, hasta el ejercicio más antiguo para el que se posea información. De esta forma, el ajuste por el efecto acumulado de las variaciones de activos y pasivos se imputará directamente en cuentas de patrimonio neto, en concreto, en una partida de reservas, salvo que afecte a un ingreso o gasto que se hubiera imputado en los ejercicios previos directamente en otra partida de patrimonio neto. Además, la mencionada norma de valoración obliga a modificar las cifras afectadas de los ejercicios a los que se refiere el cambio contable.

Es, precisamente, con respecto a esta última exigencia de la norma, donde el estado de cambios en el patrimonio neto resulta imprescindible. En este sentido, las normas de elaboración del estado establecen que, cuando se advierta un error en el ejercicio al que se refieren las cuentas anuales que corresponda a un ejercicio anterior al comparativo, se informará en la memoria y se incluirá el correspondiente ajuste en el epígrafe A.II Ajustes por errores 200X-2 y anteriores, del Estado total de cambios en el patrimonio neto. Así se habrá conseguido que el patrimonio inicial del ejercicio comparativo recoja ya la rectificación del error. Si el error correspondiera al ejercicio comparativo, el ajuste se incluiría en el epígrafe C.III Ajustes por errores 200X-1, consiguiéndose, en este caso la presentación correcta del patrimonio inicial del ejercicio actual.

Idénticas reglas a las anteriores se aplicarán en el caso de cambios en los criterios contables.

\section{Ejemplo no 2.- Corrección de errores}

Supongamos que la sociedad MORSA adquirió una máquina a comienzos de XO por importe de 96.000€, que ha venido amortizando linealmente a un ritmo del 10\% anual, habiendo estimado un valor residual al final de su vida útil de 8.000€.

A finales de X3, se considera que la vida útil estimada estaba incorrectamente calculada, siendo realmente de 8 años. Se mantiene el mismo valor residual.

\section{Solución.-}

En los ejercicios anteriores (X0, X1 y X2), la sociedad MORSA registró como amortización $10 \%(96.000-8.000)=8.800 € /$ año, es decir, 26.400€ en total.

La amortización que debería haberse registrado sería: $\quad(96.000-8.000) / 8=11.000 € /$ año es decir, 33.000€ en total. 
La diferencia entre la amortización acumulada registrada y la amortización acumulada correcta sería, por lo tanto, de $6.600 €$.

Esa diferencia, de acuerdo con las normas de valoración, se llevará al patrimonio neto a finales de X3, de la siguiente manera:

$6.600,0 0 \longdiv { 1 1 3 \text { Reservas voluntarias } }$

1)

\begin{tabular}{ccc}
$6.600,00$ & a & $\begin{array}{c}281 \text { Amortización acumulada del } \\
\text { inmovilizado material }\end{array}$ \\
\hline
\end{tabular}
$6.600,00$

Por la amortización del ejercicio X3 se registrará lo siguiente:

(1)

11.000,00 681 Amortización del inmovilizado

a $\overline{281 \text { Amortización acumulada del }}$

$\begin{array}{lll}\text { material } & \text { inmovilizado material } & 11.000,00\end{array}$

La forma de ajustar dicho error en el ETCPN sería en las filas que a continuación se detallan:

- A.II Ajustes por errores en 200x-2 y anteriores:

$[11.000+11.000-(8.800+8.800)]=4.400 €$

importe que figuraría en negativo en la columna reservas voluntarias

- C.II Ajustes por errores 20x-1:

$11.000-8.800=2.200 €$

importe también en negativo en la columna reservas voluntarias

\section{Ejemplo n ${ }^{0}$ 3.- Presentación del Estado de Cambios en el Patrimonio Neto}

El balance de situación de la sociedad TALSA presenta, a 31-12-08, las siguientes cuentas dentro del patrimonio neto:

- Capital social: 500.000€, correspondientes a 50.000 acciones de $10 €$ de valor nominal. El desembolso pendiente por acción asciende al 20\% del nominal.

- Prima de emisión: $125.000 €$.

- Reservas: 20.000€.

- Resultado del ejercicio: 15.000€.

Durante el ejercicio 2009 se realizaron las siguientes operaciones con efecto en el patrimonio neto:

- Los accionistas desembolsaron los dividendos pasivos pendientes.

- Se realizó una ampliación de capital en la proporción de 1 nueva por cada 10 antiguas, liberadas en un $20 \%$ con cargo a reservas y el resto en efectivo.

- Al final del ejercicio se adquirieron 2.000 acciones propias a 25€/acción.

- Se distribuyó el resultado del ejercicio anterior de la siguiente forma:

- A reservas: 6.500

- A dividendos: 8.500

- Al final del ejercicio se recibió una subvención de la Comunidad Autónoma donde tiene su sede la sociedad. La citada subvención tiene un importe de $40.000 €$ y ha financiado la compra de maquinaria diversa, a la que se estima una vida útil de 4 años (tipo impositivo: $30 \%$ ). 
- El valor razonable de los títulos de la cartera de disponibles para la venta, que se adquirieron durante el ejercicio por 60.000€, disminuyó al cierre en 7.500€ (tipo impositivo: $30 \%$ ).

- El resultado del ejercicio fue de -5.000€.

Ejercicio 2010:

- Se recibe una subvención de los socios por importe de 2.000€ para compensar una parte de las pérdidas acumuladas.

- El resto de las pérdidas se compensan con cargo a reservas.

- Se venden todos los títulos de la cartera de disponibles para la venta en 55.000€.

- Vende la totalidad de las acciones propias a 30€/acción.

- Se distribuye un beneficio a cuenta del resultado del ejercicio de 5.000€.

- El resultado del ejercicio asciende a $12.000 €$.

Se pide: Presentar el Estado de cambios en el patrimonio neto correspondiente a 2009 y 2010.

Solución.-

ESTADO DE CAMBIOS EN EL PATRIMONIO NETO CORRESPONDIENTE AL EJERCICIO TERMINADO EL 31-12-09

A) Estado de ingresos reconocidos correspondiente al ejercicio terminado el 31-12-09

A) RESULTADO DE LA CUENTA DE PÉRDIDAS Y GANANCIAS

$(5.000)$

B) INGRESOS Y GASTOS IMPUTADOS DIRECTAMENTE AL

PATRIMONIO NETO

I. Por valoración de instrumentos financieros

1. Activos financieros disponibles para la venta

2. Otros ingresos/gastos

II. Por coberturas de flujos de efectivo

III. Subvenciones, donaciones y legados recibidos

IV. Por ganancias y pérdidas actuariales y otros ajustes

V. Efecto impositivo

Total ingresos y gastos imputados directamente en el patrimonio neto

C) TRANSFERENCIAS A LA CUENTA DE PÉRDIDAS Y GANANCIAS

VI. Por valoración de instrumentos financieros

1. Activos financieros disponibles para la venta

2. Otros ingresos/gastos

VII. Por coberturas de flujos de efectivo

VIII. Subvenciones, donaciones y legados recibidos

IX. Efecto impositivo

Total transferencias a la cuenta de pérdidas y ganancias 0

TOTAL DE INGRESOS Y GASTOS RECONOCIDOS

17.750 
La interpretación de la cifra "total de ingresos y gastos reconocidos" sería la siguiente: La empresa ha reconocido en la cuenta de pérdidas y ganancias una pérdida de $5.000 €$, pero ha imputado directamente al patrimonio neto ingresos y gastos por un importe total de $22.750 €$, por lo que el resultado total del ejercicio asciende a $17.750 €$.

La contabilización de las operaciones con reflejo en el estado de ingresos y gastos reconocidos, que explican la presentación del estado anterior son las siguientes:

a) Contabilización relativa a la subvención de capital:

Por la recepción de la subvención:

\begin{tabular}{lll}
$40.000,00$ & 57 Tesorería & a $\begin{array}{c}940 \text { Ingresos de subvenciones } \\
\text { oficiales de capital }\end{array}$ \\
\hline
\end{tabular}
$40.000,00$

Por el reconocimiento del efecto impositivo de la subvención recibida:

\begin{tabular}{|c|c|c|}
\hline $12.000,00$ & $\begin{array}{l}8301 \text { Impuesto diferido } \\
0,3 \times 40.000\end{array}$ & $\begin{array}{c}479 \text { Pasivos por diferencias } \\
\text { temporarias imponibles }\end{array}$ \\
\hline
\end{tabular}

El efecto impositivo de la subvención, coherentemente con el tratamiento aplicado a la misma, se imputa directamente al patrimonio neto.

Por la regularización de las cuentas de los grupos 8 y 9 al cierre del ejercicio:

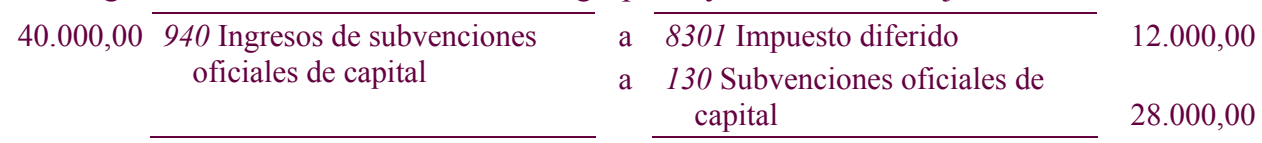

De esta manera, la cuenta Subvenciones oficiales de capital aparece por el importe neto del efecto impositivo.

b) Contabilización relativa a las inversiones financieras disponibles para la venta:

Por la valoración a valor razonable de los títulos al cierre del ejercicio:

$$
\begin{gathered}
7.500,00 \begin{array}{c}
800 \text { Pérdidas en activos financieros } \\
\text { disponibles para la venta }
\end{array} \\
\text { a }
\end{gathered}
$$
540 Inversiones financieras a corto plazo en instrumentos de patrimonio

Por el efecto impositivo del ajuste de valoración, que se imputará al patrimonio neto, al relacionarse con una transacción que también se ha imputado al mismo:
$2.250,00 \quad 4740$ Activos por diferencias temporarias deducibles $0,3 \times 7.500$
a 8301 Impuesto diferido

Por la regularización al cierre de las cuentas de los grupos 8 y 9 en la cuenta de patrimonio neto "133. Ajustes por valoración en activos financieros disponibles para la venta":
$2.250,008301$ Impuesto diferido
a 800 Pérdidas en activos financieros
5.250,00 133 Ajustes por valoración en disponibles para la venta
$7.500,00$ activos financieros disponibles para la venta 


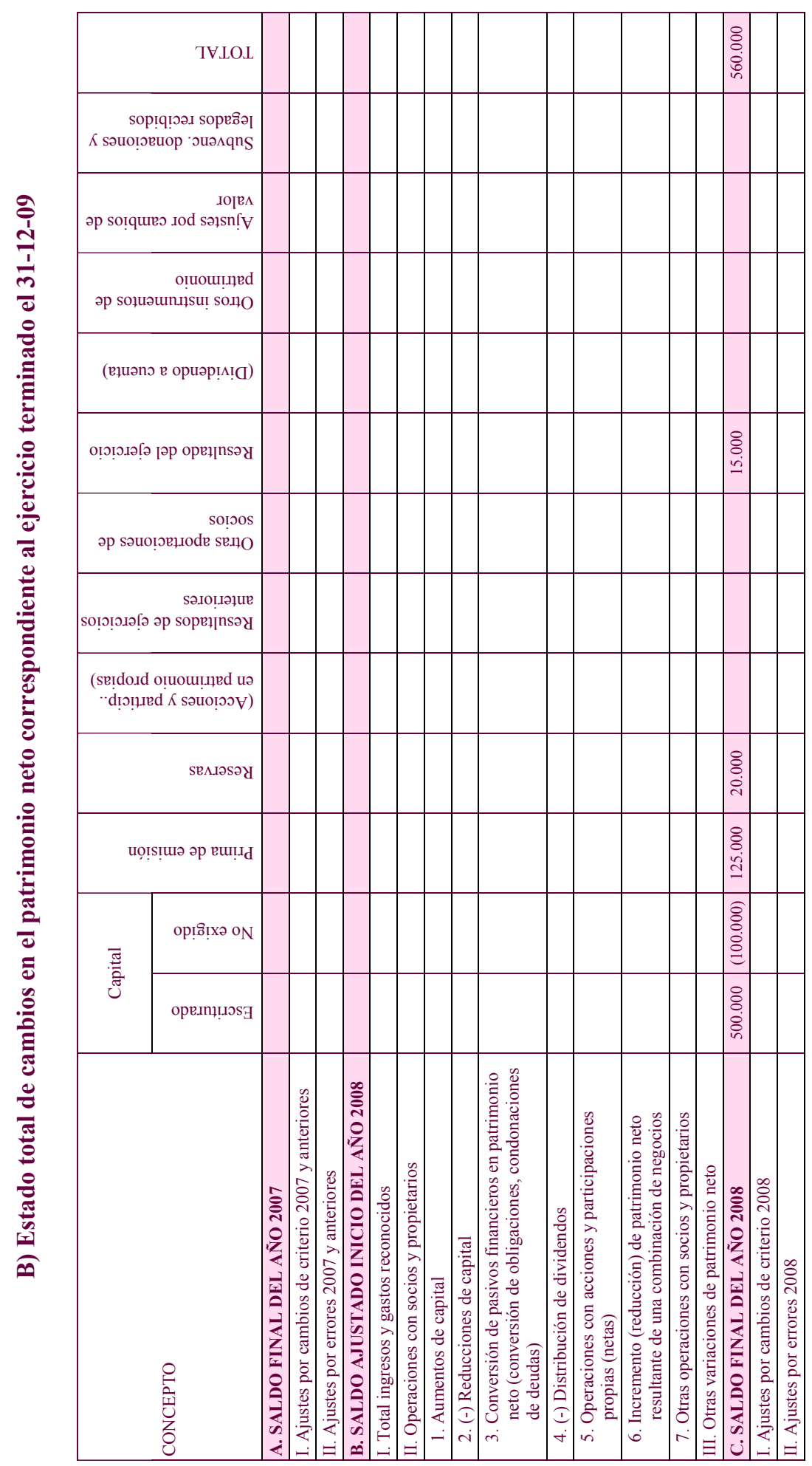




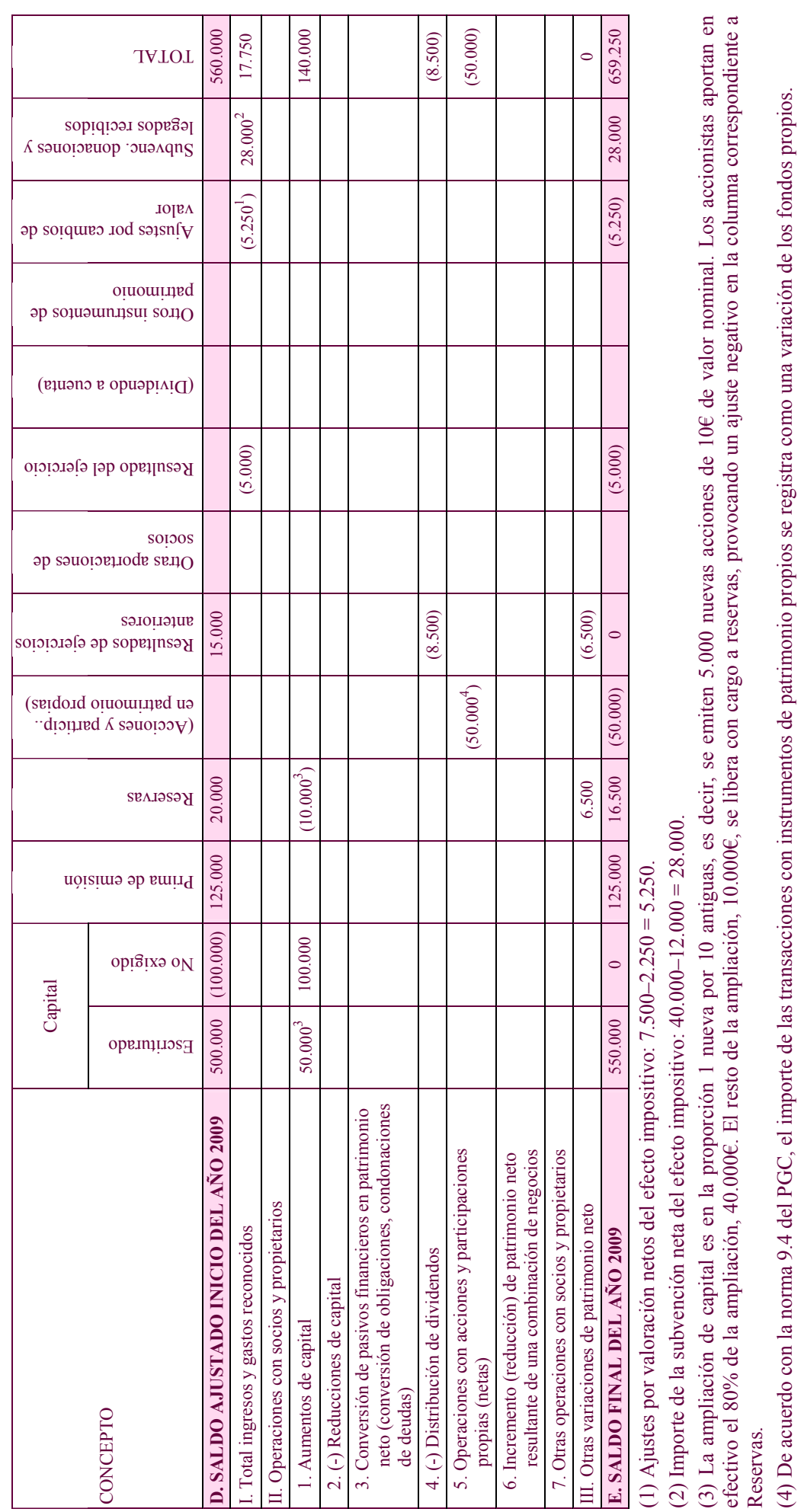


ESTADO DE CAMBIOS EN EL PATRIMONIO NETO CORRESPONDIENTE AL EJERCICIO TERMINADO EL 31-12-10

A) Estado de ingresos reconocidos correspondiente al ejercicio terminado el 31-12-10

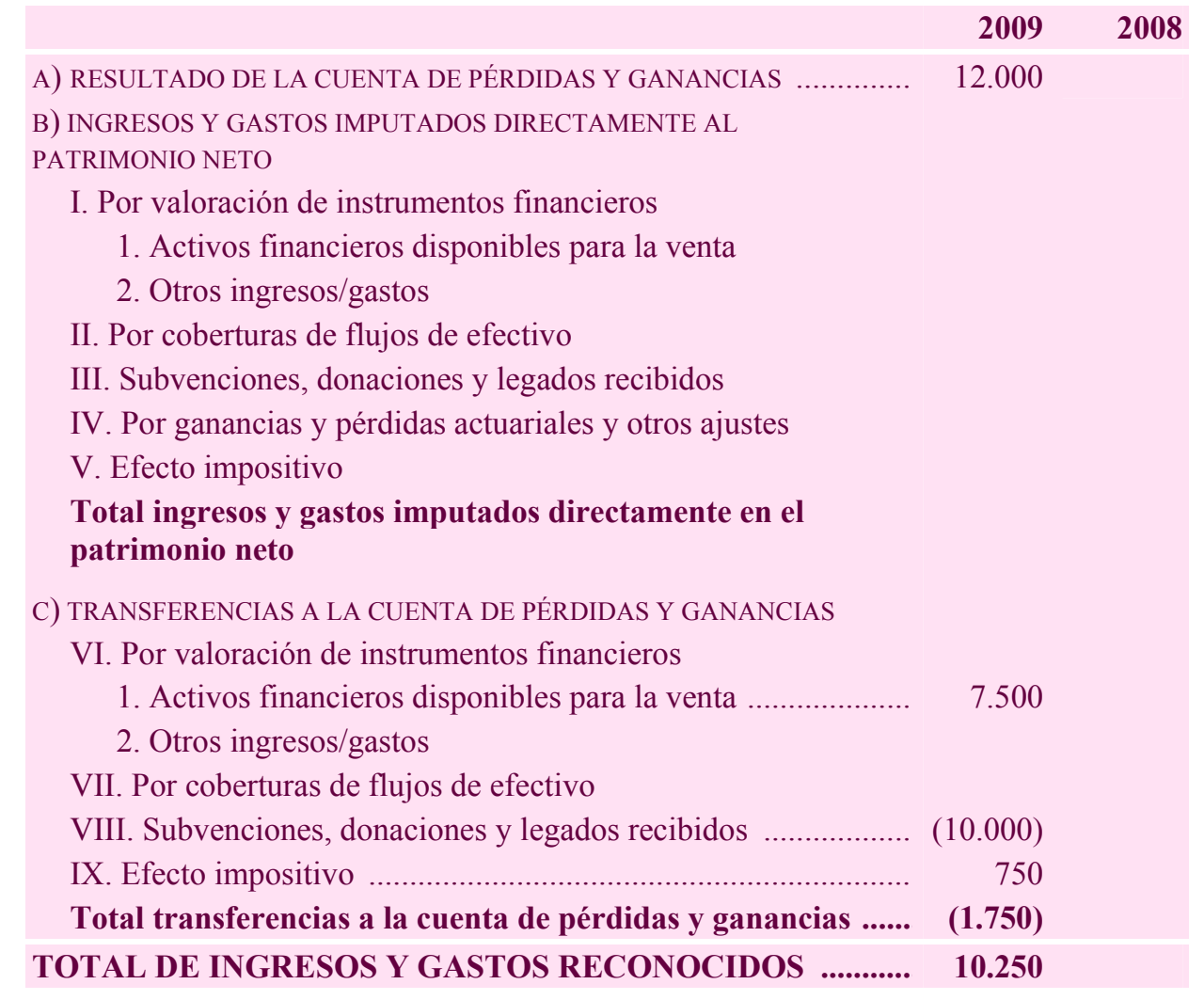

El total de los ingresos y gastos reconocidos en el ejercicio es de 10.250, pues del saldo total de pérdidas y ganancias, 12.000 , un importe neto total de 1.750 corresponde a ingresos que ya habían sido reconocidos en el patrimonio neto en el ejercicio anterior.

En este caso, la contabilización de las operaciones con efecto en el estado de cambios en el patrimonio neto sería la siguiente.

a) Operaciones relativas a la subvención:

Por la imputación de la subvención al resultado del ejercicio:

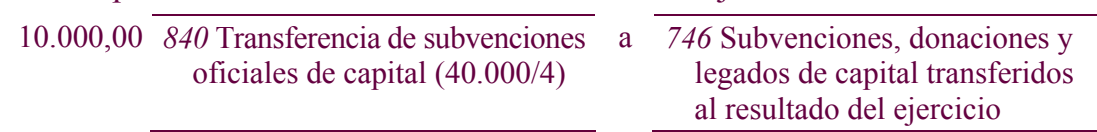

$10.000,00$

La subvención se traspasa al resultado del ejercicio en la misma proporción que se amortiza el activo subvencionado, en este caso, linealmente en cuatro años.

Por el efecto impositivo del traspaso a resultados: 


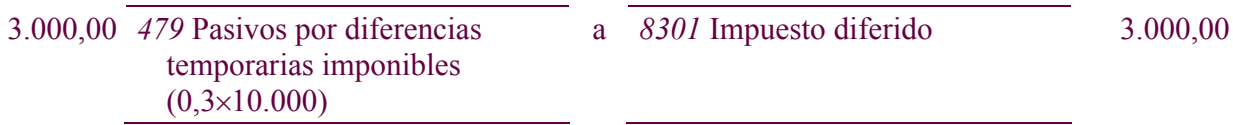

Por la regularización de las cuentas de los grupos 8 y 9 :

$\begin{array}{lll}3.000,00 & 8301 \text { Impuesto diferido } & \text { a } \\ 7.000,00 & 130 \text { Subvenciones oficiales de }\end{array} \quad \begin{gathered}840 \text { Transferencia de subvenciones } \\ \text { oficiales de capital }\end{gathered}$

b) Operaciones relativas a la venta de los títulos de la cartera de disponibles para la venta:

$55.000,0 0 \longdiv { 5 7 \text { Tesorería } }$ a 540 Inversiones financieras a corto plazo en instrumentos de patrimonio

a 766 Beneficios en participaciones y valores representativos de deuda

Por el traspaso a resultados de las pérdidas del ejercicio anterior:

\begin{tabular}{cccc}
\cline { 2 - 3 } $\begin{array}{c}\text { 7.500,032 Pérdidas de disponibles para } \\
\text { la venta }\end{array}$ & $\begin{array}{r}902 \text { Transferencia de pérdidas de } \\
\text { activos financieros disponibles } \\
\text { para la venta }\end{array}$ \\
\hline
\end{tabular}

Por la reversión del efecto impositivo contabilizado el pasado ejercicio:

\begin{tabular}{|c|c|c|c|}
\hline \multirow[b]{2}{*}{$2.250,00$} & \multirow{2}{*}{8301 Impuesto diferido } & \multirow[b]{2}{*}{$\mathrm{a}$} & \multirow[b]{2}{*}{$\begin{array}{l}4740 \text { Activos por diferencias } \\
\text { temporarias deducibles }\end{array}$} \\
\hline & & & \\
\hline & a112acion & & \\
\hline \multirow[t]{2}{*}{$7.500,00$} & \multirow{2}{*}{$\begin{array}{l}902 \text { Transferencia de pérdidas en } \\
\text { activos financieros disponibles } \\
\text { para la venta }\end{array}$} & $\mathrm{a}$ & 8301 Impuesto diferido \\
\hline & & a & $\begin{array}{l}133 \text { Ajustes por valoración en } \\
\text { activos financieros disponibles } \\
\text { para la venta }\end{array}$ \\
\hline
\end{tabular}




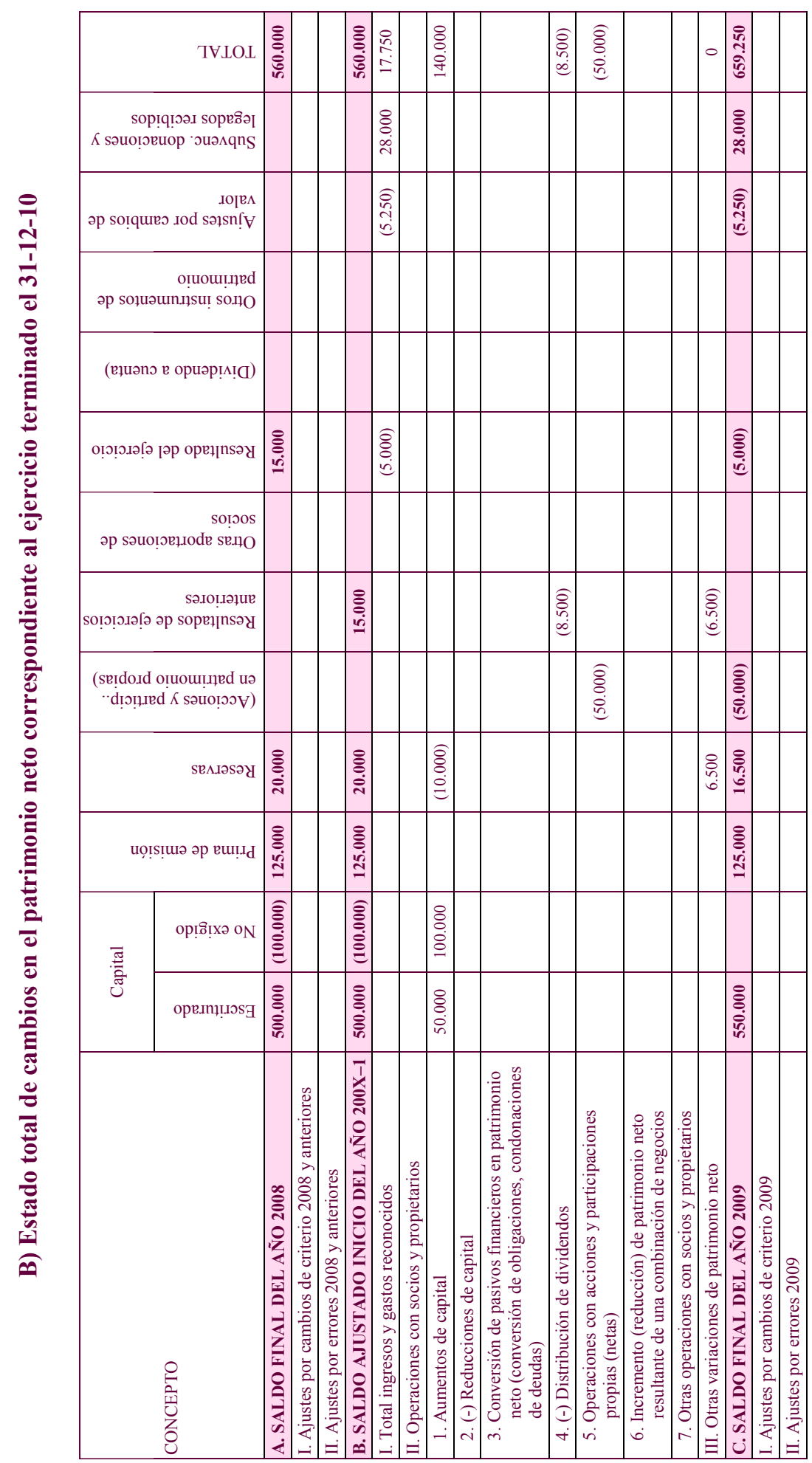




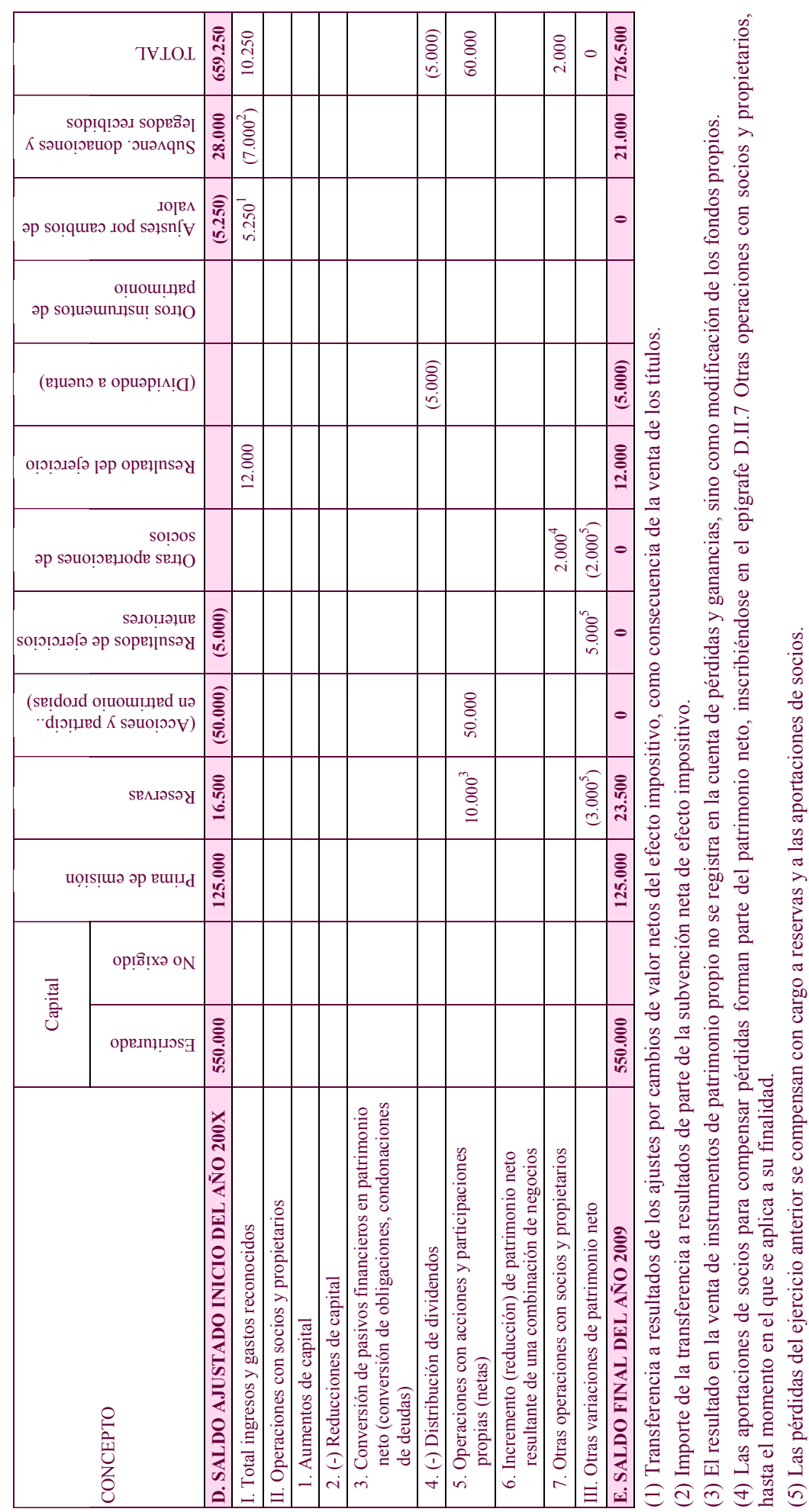


BIBLIOGRAFÍA

Amador, S. y I. Carazo (2008) Plan General de Contabilidad. Comentarios y casos prácticos, $9^{a}$ edición. Madrid: CEF.

Corona Romero, e.; J. Talavero Sanguino, f. García martínez, Á. Monzón SÁnCHEZ, R. López Galindo, J. Clavo GonZÁlez-VAllinas y J. VARELA CRuZEiro (2005) Aplicación de las normas internacionales de contabilidad adoptadas por la Unión Europea (NICes). Valencia: CISS.

DOSSIER PRÁCTICO FRANCIS LEFEBVRE (2008) Sistemática Memento. Plan General Contable. 125 Supuestos prácticos. Madrid: Ediciones Francis Lefebvre.

GómEZ, F. (2006) NIC/NIIF. Ejercicios resueltos comentados. Barcelona: Ediciones Gestión 2000.

IBÁÑEZ JimÉNEZ, E.M y L. PARTE ESTEBAN (2008) "El estado de flujos de efectivo. Presentación y análisis", Partida Doble, n 199, mayo, pp. 64-79.

INTERNATIONAL ACCOUNTING STANDARDS BOARD (2006) Normas Internacionales de información financiera (NIIF), texto completo de las Normas Internacionales de Información Financiera emitidas a 1 de enero de 2006, traducción al español publicada por CISS-PRAXIS con la autorización de la IASCF.

KPMG INTERNATIONAL FINANCIAL REPORTING GROUP (2006) Las NIIF comentadas. Guía práctica de KPMG para comprender las Normas Internacionales de Información Financiera. Navarra: Thomson-Aranzadi.

PRICE-WATERHOUSE-COOPERS (2004) Normas Internacionales de Contabilidad 2005-2006. Desarrollo y Comentarios. Madrid: Ediciones Frances Lefebvre.

ReJón LóPEZ, M. (2007) "Estado de Cambios en el Patrimonio Neto en el nuevo PGC(I). Los ingresos y gastos reconocidos en el patrimonio neto", Partida Doble, $\mathrm{n}^{\circ} 188$, mayo, pp. 44-61.

- (2007) "Estado de Cambios en el Patrimonio Neto en el nuevo PGC(II). El ECTPN y la información en la memoria", Partida Doble, $\mathrm{n}^{\circ} 189$, junio, pp. 32-43.

ROMERO FRÍAS, E. (Coord.) (2008) Cambios en el PGC. Madrid: LID Editorial Empresarial S.L. 